ISSN: 2277-3754

ISO 9001:2008 Certified

International Journal of Engineering and Innovative Technology (IJEIT)

Volume 10, Issue 1, July 2020

\title{
Mapping and Analysis of Predictive Factors of Road Traffic Accidents in the City of Yaounde, Cameroon
}

\author{
WOUNBA Jean François ${ }^{1 *}$ NKENG George ELAMBO ${ }^{2 * *}$ NONO TCHAYA Pollack Ferguson $^{3 * * *}$
}

1-Department of Town Planning, National Advanced School of Public Works, Ministry of Public Works, P.O. Box. 510, Yaoundé, Cameroon

2-Director of National Advanced School of Publics Works, P.O Box. 510, Yaounde Cameroon

3-Department of Civil engineering, National Advanced School of Public Works, P.O. Box 510, Yaoundé Cameroon

\begin{abstract}
The objective of this paper was to identify the factors determining the severity of road traffic accidents by mapping the spatial concentrations of road traffic accidents in the city of Yaounde (Cameroon), in order to propose an effective information system capable of assisting in the decision-making process to prevent road traffic accidents. The methodology used in this study was composed of two phases. The first, consisted in identifying the factors influencing the severity of road traffic accidents in the city of Yaounde using statistical methods and the second, consisted in determining the accident-prone areas of the city of Yaounde using simple road safety indicators. The results showed that the black spots identified present similar problems which are the degradation of road infrastructure and the inappropriate behaviourof the citizens. The analysis of factors predictive of severity showed that the most vulnerable users are aged between 15 and 25 years and between 35 and 45 years, the major causes of road traffic accidents are recklessness of pedestrians; and the most involved in injury and death accidents are two-wheelers and motorised three-wheelers. The study not only makes it possible to elucidate the human factors significantly associated with the severity and lethality of road traffic accidents, but also to highlight the quality of the data collected by the police.
\end{abstract}

Keywords: predictive factors, road traffic accident, severity, spatial concentration.

\section{INTRODUCTION}

Few subjects in the world provide as much data as road traffic accidents (RTAs) [1]. Since the advent of motorization, information has been collected on approximately one billion road traffic crashes worldwide, covering all countries, both developed and developing. Despite so much data, many questions remain unanswered because the factors of interest for data collection have not been well defined at the base or the data are not sufficiently reliable, complete or accessible.

Manuscript received: 25 June 2020

Manuscript received in revised form: 24 July 2020

Manuscript Accepted: 08 August 2020

Manuscript Available online: 15 August 2020
Methods have been developed to correct these observed deficiencies in data quality as best as possible, such as the capture and recapture method, which allows data from several sources to be cross-referenced, thus eliminating duplicates [2][3][4], other research make it possible to classify. Road traffic accident are injuries according to a scale defined by the AIS (Abbreviated Injury Scale) [1]. With regard to the identification of conflict zones (black zone), it requires the use of adequate statistical methods to obtain reliable results [5]. In the literature, there are several approaches such as spatial analysis, in which methods such as spatial autocorrelation is used, which studies the behaviour of areas adjacent to accident-prone zones and establishes whether or not dependency relationships exist between an accident-prone zone and its neighbourhood [6]. We also have Bayesian approaches which are complex methods for identifying problem sites with a predefined distribution on a parameter $\pi(\theta \mathrm{i} / \eta)$, where $\eta$ is a parameter vector describing the potential factors responsible for accidents and $\theta_{-} \mathrm{i}$ is the mean of accidents [7][8][9][10]. On the other hand, simple road safety methods are more practical methods that use basic data and are easily applicable [11][12]. One of the first steps in improving a road network is to identify problem sites and implement a road safety project.

Thus, the aim of this paper is to elucidate the factors determining the severity of road traffic accidents and mapping the spatial concentrations of RTAs in the city of Yaounde (Cameroon).

\section{A. Study Site}

\section{METHODOLOGY}

Yaounde is the political capital of Cameroon. It covers an area of $304 \mathrm{~km}^{2}$ of which $183 \mathrm{~km}^{2}$ is urbanised. Since the first census, the population of the city of Yaounde has continued to grow at an exponential rate. In 1960, at the time of Cameroon's independence, the city of Yaounde had only about 100,000 inhabitants by 1987 , it had grown 
ISSN: 2277-3754

ISO 9001:2008 Certified

International Journal of Engineering and Innovative Technology (IJEIT)

Volume 10, Issue 1, July 2020

to 649,252 inhabitants and in recent times (2018), it was estimated at about 3,500,000 inhabitants.

\section{B. Sampling}

The sample used for this article is an exhaustive collection of road traffic accidents that occurred in the city of Yaounde from October 2018 to September 2019. These data were made available by the statistics office at the General Delegation for National Security (GDNS), which is the headquarters of the database of road traffic accidents in urban areas throughout the national territory. As the database had some technical problems that caused it to stop functioning during the study period, the data collected were recorded using Excel software based on the template of the SFINGE software used for the database. This data collection lasted three (03) weeks during which 483 accident reports were consulted and recorded.

\section{Analysis}

The methodology used in this paper consists of two phases, the first phase is a statistical analysis to determine factors predictive of road traffic accident severity, and the second phase is an identification of black areas using modified road safety indicators and mapping of these black areas using GIS.

\section{Statistical analysis}

The analysis tool that will be used in this paper is the Microsoft EXCEL software of the Office 16 package for accident severity analysis and the SPSS statistical analysis software to perform the statistical analysis using the logistic regression analysis. Logistic regression is defined as a technique for fitting a regression surface to data when the dependent variable is dichotomous (variable with only two modality).

\section{Identification and mapping of black areas}

Cameroon does not have a standard reference or approach to identify accident prone locations, this research adopted a simple statistical approach to identify locations with a high accident risk, i.e. comparison with a threshold value. Any site with an observed number of accidents above the threshold value is classified as a problematic location.

The problematic sites were identified using the modified simple road safety indicators methods which are the accident frequency (Eq. 1) and the injury severity density (ISD) (Eq. 2). The weightage points used for the ISD were adjusted to the local context based on those developed in Malaysia which are valid for developing countries[13]

\begin{tabular}{|c|c|}
\hline Frequency $=$ Number of accident $/$ length $(\mathrm{km})$ & (1) \\
\hline $\begin{array}{c}\text { Injury Severity Index }=(6 \times \text { Fatal+3xInjury+Property } \\
\text { damage }) /(\text { Length } \mathrm{x} \text { year })\end{array}$ & (2) \\
\hline Threshold value $=\max (\mathrm{x}, \mathrm{m})$ & (3) \\
\hline
\end{tabular}

The identification process was as follows:

- Using a geographic information system (GIS), the recorded accidents were georeferenced using Google Earth and transferred to ArcGis 10.4 for processing and the production of the accidentprone locations map;

- The accidents having been georeferenced, interest was laid on the areas of accident concentration, and these areas (crossroads and sections) were selected (length, number and type of accidents recorded at these locations);

- Was then calculated the frequency of accidents in these different areas, and potential problem areas identified. A section is defined as problematic if are present more than 4 accidents for $500 \mathrm{~m}$ length and an intersection is defined as problematic if are present more than 4 accidents;

- These problematic sites are refined using the ISD criteria. After the calculation of the ISD value of the site, it is compared to a threshold value given by Eq. 3 .

Where $\mathrm{x}=$ the mean of the total accidents recorded on problematic sites

$\mathrm{m}=$ the median of the total accidents recorded on problematic sites

\section{RESULTS}

\section{A. Multivariate Study by Logistic Regression of Severity}

Table 1, is the result of logistic regression analysis of the risk factors for the severity (death or serious injury) of road traffic accidents obtained from SPSS.

Table 1. Relationship between accident risk factors and accident severity

\begin{tabular}{lcccc}
\hline Variables & Frequency & OR $^{*}$ & IC95\% $^{*}$ & P \\
\hline Age category & & & & \\
{$[0-25$ years [ } & 68 & 3.03 & $0.926-9.918$ & 0.067 \\
\hline
\end{tabular}




\section{IVEIT}

ISSN: 2277-3754

ISO 9001:2008 Certified

International Journal of Engineering and Innovative Technology (IJEIT)

Volume 10, Issue 1, July 2020

\begin{tabular}{|c|c|c|c|c|}
\hline \multirow[b]{2}{*}{ Variables } & & \multirow[b]{2}{*}{$\mathrm{P}$} \\
\hline & Frequency & $\mathrm{OR}^{*}$ & $\mathrm{IC}_{95 \%}$ & \\
\hline$[35-45$ years [ & 285 & 0.295 & $0.1-0.869$ & 0.027 \\
\hline$[45-55$ years [ & 172 & 0.471 & $0.157-1.412$ & 0.179 \\
\hline \multicolumn{5}{|l|}{ Human causes } \\
\hline Lack of control & 67 & 1.1 & $0.533-2.27$ & 0.797 \\
\hline Excess speed & 109 & 0.71 & $0.274-1.855$ & 0.488 \\
\hline Pedestrian carelessness & 15 & 0.134 & $0.024-0.750$ & 0.022 \\
\hline Dangerous manoeuvring & 125 & 0.853 & $0.465-1.565$ & 0.607 \\
\hline Inattention & 134 & 0.667 & $0.304-1.464$ & 0.313 \\
\hline Dangerous overtaking & 127 & 2.689 & $0.871-8.71$ & 0.085 \\
\hline \multicolumn{5}{|l|}{ Month } \\
\hline January & 71 & 0.980 & $0.492-1.952$ & 0.955 \\
\hline February & 91 & 0.876 & $0.447-1.717$ & 0.699 \\
\hline March & 97 & 1.448 & $0.649-3.228$ & 0.366 \\
\hline April & 61 & 0.605 & $0.292-1.253$ & 0.176 \\
\hline May & 61 & 0.028 & $0.003-0.227$ & $<0.001$ \\
\hline December & 11 & 1 & 1 & \\
\hline \multicolumn{5}{|l|}{ Day of the week } \\
\hline Monday & 67 & 4.167 & $1.529-11.35$ & 0.005 \\
\hline Tuesday & 58 & 1.119 & $0.431-2.91$ & 0.817 \\
\hline Wednesday & 76 & 1.141 & $0.485-2.68$ & 0.763 \\
\hline Thursday & 63 & 2.126 & $0.832-5.43$ & 0.115 \\
\hline Friday & 80 & 0.891 & $0.374-2.12$ & 0.794 \\
\hline Saturday & 71 & 1.285 & $0.520-3.17$ & 0.587 \\
\hline Sunday & 65 & 1 & 1 & \\
\hline \multicolumn{5}{|l|}{ Vehicle } \\
\hline Car & 573 & 1.358 & $0.839-2.199$ & 0.212 \\
\hline Truck/Bus & 152 & 1.945 & $1.096-3.452$ & 0.023 \\
\hline Bicycle/Motorcycle & 109 & 6.158 & $3.482-10.89$ & 0.000 \\
\hline other & 186 & 1.0 & 1.0 & \\
\hline
\end{tabular}

*Odds-Ratio

\section{B. Accident Prone Locations of Yaounde}

Table 2 is the result of identification of problematic site which are represented in Figure

Table 2.Problematic site

\begin{tabular}{|l|c|c|c|c|c|c|c|}
\hline Codes & Fatal & Injury & Pdo & Total & Length(m) & Frequency & $\begin{array}{c}\text { Injuryseverity } \\
\text { index }\end{array}$ \\
\hline T 1 & 1 & 0 & 2 & 3 & 0,92 & 3 & 2,45 \\
\hline T 2 & 0 & 1 & 2 & 3 & 0,9 & 3 & 1,50 \\
\hline T 3 & 0 & 2 & 6 & 8 & 0,392 & 20 & 0,59 \\
\hline
\end{tabular}




\section{DJEIT}

ISSN: 2277-3754

ISO 9001:2008 Certified

International Journal of Engineering and Innovative Technology (IJEIT)

Volume 10, Issue 1, July 2020

\begin{tabular}{|l|l|l|l|l|l|l|l|} 
T 5 & 0 & 2 & 2 & 4 & 0,31 & 13 & 0,62 \\
\hline T 6 & 0 & 1 & 3 & 4 & 0,12 & 33 & 0,18 \\
\hline T 9 & 1 & 1 & 3 & 5 & 0,42 & 12 & 1,01 \\
\hline T 10 & 0 & 3 & 5 & 8 & 0,419 & 19 & 0,73 \\
\hline T 12 & 1 & 2 & 9 & 12 & 0,766 & 16 & 1,34 \\
\hline T 15 & 0 & 3 & 1 & 4 & 0,306 & 13 & 0,77 \\
\hline T 19 & 0 & 5 & 6 & 11 & 0,788 & 14 & 1,50 \\
\hline T 27 & 3 & 2 & 4 & 9 & 1,05 & 9 & 3,27 \\
\hline C 2 & 1 & 0 & 3 & 4 & 1 & 4 & 2,25 \\
\hline C 9 & 2 & 0 & 5 & 7 & 1 & 7 & 2,43 \\
\hline C 11 & 2 & 1 & 2 & 5 & 1 & 5 & 3,40 \\
\hline C 12 & 1 & 2 & 1 & 4 & 1 & 4 & 3,25 \\
\hline
\end{tabular}

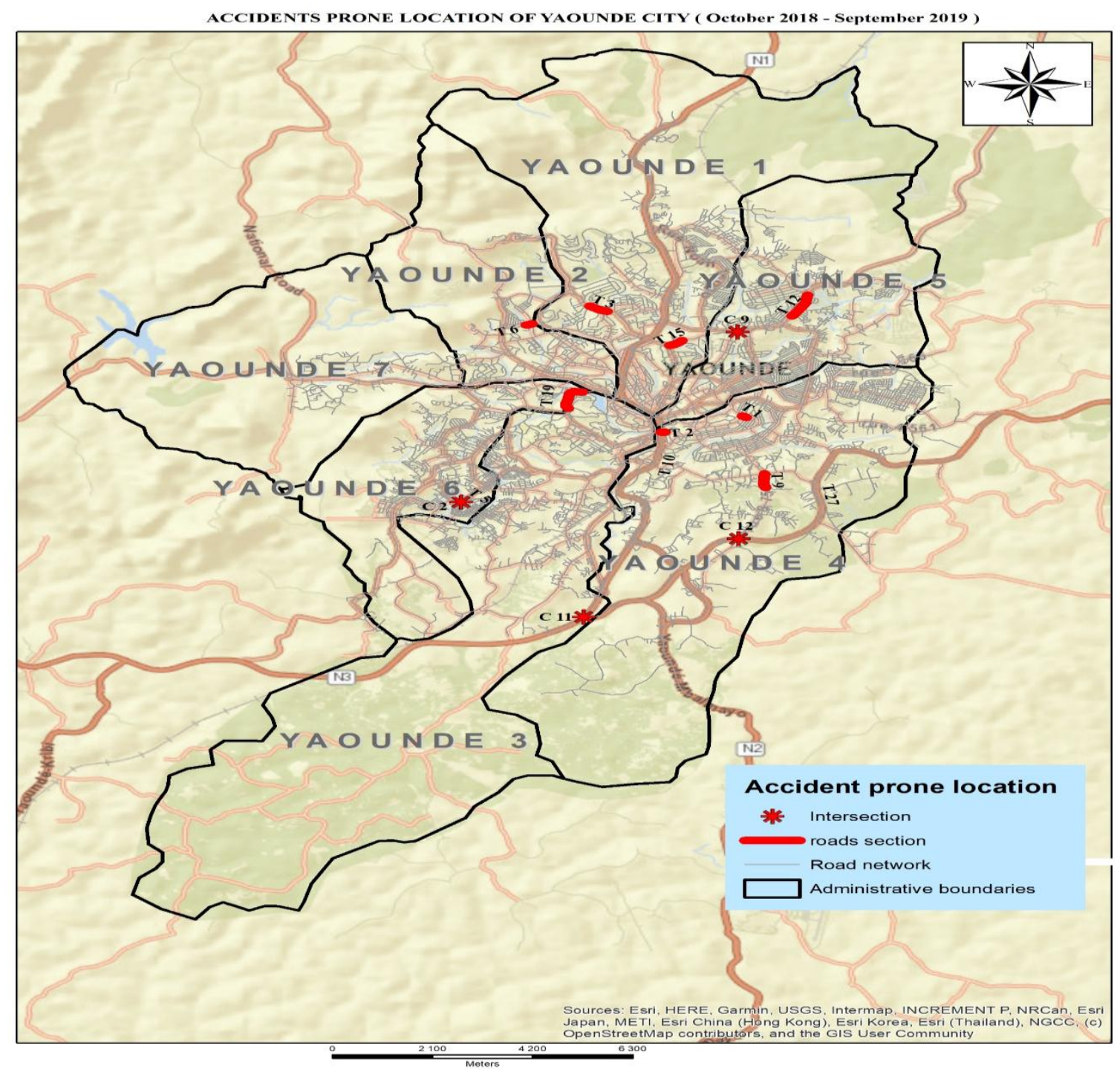

Fig 1 .Accident prone location 
ISSN: 2277-3754

ISO 9001:2008 Certified

International Journal of Engineering and Innovative Technology (IJEIT)

Volume 10, Issue 1, July 2020

\section{DISCUSSION}

From the analysis of Table 2, it appears that the nature of road accidents does not have an impact on the crash frequency because sites $\mathrm{T} 1$ and $\mathrm{T} 2$ of approximately the same length have the same frequency, although recording accidents of a different nature. On the other hand, site T1 recording a fatal accident has a severity index 1.63 times greater than that of site $\mathrm{T} 2$, which does not record any fatal accidents. This reveals the urgency to act on this site $\mathrm{T} 1$ and all the sites that recorded fatalities.

Site T6 has the highest frequency of accidents, but in contrast has the lowest severity index, which can be explained by the high number of accidents with material damage only that have occurred on this site. Further observation of the site should be performed to understand the causes of this minor accidents.

The intersections have the highest severity indices $(\mathrm{C} 2=2.25, \mathrm{C} 9=2.43, \mathrm{C} 11=3.40, \mathrm{C} 12=3.25)$, which is due to the lack of intersection layout observed at these locations.

A very significant association was revealed in the comparison of the number of victims to the accident causes. Specifically, some human causes were identified as being more at risk of the severity of the accident than others. In our study, pedestrian recklessness presented the greatest risk of severity and death (related to the vulnerability of the pedestrian himself), followed by excessive speed and driver inattention.

The analysis of factors predictive of severity revealed a vulnerability of $0-25$-yearold's $(p=0.067)$ and 35-45yearold's $(p=0.027)$. These figures could be explained by the fact that, the city of Yaounde is the capital of Cameroon, and it is a cosmopolitan city appealing to young people who are attracted by the opportunities it offers. This youthful population is in highly mobile and mobility increases the risk of accidents exposure.

Among the causes of accidents, pedestrian carelessness was the most important factor in the severity of RTAs $(p=0.022)$, also speeding $(p=0.007)$. This high exposure of pedestrian can be justified by the poor development of the city's road network. This is justified by lack of protective measures for pedestrians on the city's roads, such as adequate signalization and guardrails on the approach to the roads.

Among the days on which accidents occurred during the week, Monday was the most serious factor in the severity of RTAs in Yaounde $(\mathrm{p}=0.005)$.this could be explained on the one hand by the fatigue of drivers returning from week-ends, and on the other hand by the greater mobility on the roads on Mondays, with students, workers in both formal and informal sectors being more strength at beginning of the week. All this orchestrates conditions that increase the risk of accidents.
Among vehicles, motorcycles represent the riskiest factor in the seriousness of RTAs in Yaounde $(P=0.000)$, this high exposure is due to the cohabitation of heavy vehicles and motorcycles, which are vulnerable users and also the fact that the majority of these motorcyclists do not have safety equipment and are generally overloaded.

Heavy vehicles (buses, minibuses, vans, trucks) are also risk factors for the severity of RTAs in Yaounde $(\mathrm{P}=0.023)$. Heavy vehicles exposure is a consequence of the exposure of pedestrians and motorcyclists.

\section{CONCLUSION}

The overall objective of this study was to propose an effective information system to assist in decision-making and operational actions to prevent RTAs. To this end, the methodology used in this study was composed of two parts. The first phase consisted in highlighting the factors influencing the seriousness of road traffic accidents in the city of Yaounde, using statistical methods, and the second phase consisted in determining a map of accident-prone areas in the city of Yaounde using simple road safety indicators. The use of simple road safety indicators enabled us to identify fifteen (15) problem sites including eleven (11) sections and four (04) crossroads. The analysis of factors predictive of severity shows that; the most vulnerable users are aged between 15 and 25 years and between 35 and 45 years, the major causes of RTA are pedestrian carelessness and speeding, the vehicles most involved in injury and fatal accidents are twowheelers.

A methodological limitation was the assessment of severity by the police forces who donot have a clinical definition for the severity of the victims. In addition, the definition of "death" recommended by WHO which says a death due to RTA has to be recorded up to of 30 days after theRTA is not respected since generally online onsite deaths are counted and no follow up is done. The numbers of deaths and the distribution of severity of the victims could have been influenced by information provided during the completion of the reports.

It would be essential to complete this study by incorporating hospital department accident data in future studies to cross-check the data from the two data collection structures and better estimate the amount of data, in addition to taking into account the accident rate in the estimation of accident areas.

\section{REFERENCES}

[1] H. A. SANGO, "Epidémiologie et surveillance des accidents corporels de la route dans un pays en développement : Dédicaces :," 2014.

[2] J. A. Razzak and P. Stephen, "Estimating deaths and injuries due to road traffic accidents in Karachi , Pakistan , through the capture-recapture method," pp. 866-870, 1998.

[3] L. B. Meuleners, A. H. Lee, L. R. Cercarelli, and M. Legge, "Estimating crashes involving heavy vehicles in 
ISO 9001:2008 Certified

International Journal of Engineering and Innovative Technology (IJEIT)

Volume 10, Issue 1, July 2020

Western Australia , 1999 - 2000: A capture - recapture method," vol. 38, pp. 170-174, 2006.

[4] E. Amoros, J. Martin, S. Lafont, and B. Laumon, "Actual incidences of road casualties, and their injury severity , modelled from police and hospital data , France," vol. 18, no. 4, pp. 360-365, 2008.

[5] A. Mendas, S. Hamdoun, and H. Nechniche, "Identification et cartographie des concentrations spatiales des accidents de la route Application à la RN 11 ( Ouest algérien )," pp. 35-40, 2006.

[6] B. Flahaut, M. Mouchart, E. S. Martin, and I. Thomas, "The local spatial autocorrelation and the kernel method for identifying black zones: A comparative approach," Accid. Anal. Prev., vol. 35, no. 6, pp. 991-1004, 2003.

[7] L. F. Miranda-Moreno, A. Labbe, and L. Fu, "Bayesian multiple testing procedures for hotspot identification," Accid. Anal. Prev., vol. 39, no. 6, pp. 1192-1201, 2007.

[8] L. F. Miranda-Moreno, L. Fu, S. Ukkusuri, and D. Lord, "How to incorporate accident severity and vehicle occupancy into the hot spot identification process?," Transp. Res. Rec., no. 2102, pp. 53-60, 2009.

[9] S. Cafiso, G. La Cava, and A. Montella, "Safety index for evaluation of two-lane rural highways," Transp. Res. Rec., no. 2019, pp. 136-145, 2007.

[10] S. Cafiso and G. Di Silvestro, "Performance of safety indicators in identification of black spots on two-lane rural roads,” Transp. Res. Rec., no. 2237, pp. 78-87, 2011.

[11] K. Geurts, G. Wets, and B. Tom, "Clustering and profiling traffic roads by means of accident data," Proc. Eur. Transp. Con- ference 2003, Strasbourgh (France), Oct. 8-10, 2003, 2003.

[12] R. Elvik, "A survey of operational definitions of hazardous road locations in some European countries," Accid. Anal. Prev., vol. 40, no. 6, pp. 1830-1835, 2008.

[13] S. A. S. Rahim, J. M. Marjan, and W. S. Voon, Guideline on Accident-Prone Area Identification, no. 115. 2013. 